\title{
Removal of the connector on the laryngeal mask airway provides a useful alternative to the intubat- ing laryngeal mask
}

\author{
[Le retrait du connecteur du masque laryngé permet une utilisation équivalente \\ au masque laryngé d'intubation]
}

Carsten Preis MD, ${ }^{*}$ Irene Preis MD $\dagger$

Purpose: We describe two cases in which fiberoptic intubation through the standard laryngeal mask airway (LMA) was successful with large-bore tracheal tubes (TTs) when an intubating LMA (ILMA) could not be used.

Clinical features: Patient \#I, with obstructive sleep apnea, underwent elective surgical repair. His mouth opening was just under $25 \mathrm{~mm}$, but difficult intubation was not anticipated. We induced general anesthesia, easily ventilated the patient by mask, and established neuromuscular blockade. Direct laryngoscopy and attempts to insert either a \#5 or a \#4 ILMA into the mouth failed. A standard \#4 LMA, with the connector removed, was inserted, through which a $7.0 \mathrm{~mm}$ nasal RAE ${ }^{\mathrm{TM}} \mathrm{TT}$, fiberoptically guided, passed into the trachea at the first attempt.

Patient \#2, with a loosened implant after left hip arthroplasty, underwent revision prosthesis. Her neck movement was limited. We thus planned awake securing of the airway, but the patient refused. We induced anesthesia and established bag-mask-valve ventilation. The limited neck movement prevented direct laryngoscopy. Visualizing the laryngeal inlet with the fiberoptic bronchoscope (FOB) proved impossible as bloody secretions obscured the FOB's tip. Ventilation by mask was easy. As an ILMA was not available, we removed a \#5 LMA's connector and passed an $8.0 \mathrm{~mm}$ nasal RAE ${ }^{\mathrm{TM}}$ TT through the LMA. Fiberoptic-guided intubation was easy. In both cases, the remainder of the intraoperative course was uneventful.

Conclusion: A standard LMA whose connector has been removed to allow passage of TTs of $>6.0 \mathrm{~mm}$ internal diameter may be substituted for the ILMA when necessary.
Objectif : Décrire deux cas où l'intubation fibroscopique au travers du masque laryngé standard (ML) a été réussie avec des tubes trachéaux de grand calibre (TT) alors qu'un masque laryngé d'intubation (MLI) ne pouvait être utilisé.

Éléments cliniques : Le patient $n^{\circ}$ I, qui présentait une apnée du sommeil obstructive, devait subir une réparation chirurgicale. L'ouverture de sa bouche était d'un peu moins de $25 \mathrm{~mm}$, mais on n'a pas envisagé d'intubation difficile. On a induit l'anesthésie, ventilé facilement le patient au masque et procédé au blocage neuromusculaire. La laryngoscopie directe et les tentatives pour insérer dans la bouche, soit le $M L I r^{\infty} 5$, soit le $n^{\circ} 4$, ont toutes échoué. On a inséré un $M L n^{\circ} 4$ standard, sans connecteur, au travers duquel on a passé dans la trachée, dès le premier essai, un TT nasal RAETM de 7,0 mm sous guidage fibroscopique.

La patiente $n^{\circ} 2$ qui présentait un implant mobile, conséquence d'une arthroplastie de la hanche gauche, a subi une révision prothétique. Les mouvements de son cou étant limités, on a planifié une intubation vigile, mais la patiente a refusé. On a induit l'anesthésie et amorcé la ventilation manuelle au masque et au ballon. Les mouvements limités du cou ont empêché la laryngoscopie directe et la visualisation de l'entrée du larynx au moyen du fibroscope bronchique (FOB) s'est révélée impossible étant donné les sécrétions sanguinolentes qui obstruaient la pointe du FOB. La ventilation au masque était facile et comme aucun MLI n'était disponible, on a enlevé le connecteur d'un $M L$ np 5 et inséré un TT nasal RAETM de 8,0 mm au travers du ML. Ainsi, l'intubation sous guidage fibroscopique a été aisée. Dans les deux cas, le reste de l'intervention s'est bien déroulé.

Conclusion : Un ML standard dont le connecteur a été enlevé pour permettre le passage d'un TT de diamètre intérieur $>6,0 \mathrm{~mm}$ peut remplacer le $M L I$ s'il le faut.

From the Department of Anesthesiology and Intermediate Care, ${ }^{*}$ Rudolfinerhaus, Vienna, Austria, and the Department of Anesthesiology, $\uparrow$ University of Würzburg, Germany.

Address correspondence to: Dr. Carsten Preis, Department of Anesthesiology and Intermediate Care, Rudolfinerhaus, Billrothstrasse 78 ,

1190 Vienna, Austria. Phone: +43-1-36 0 36; Fax: +43-1-36 981 10; E-mail: c.preis@rudolfinerhaus.at

Accepted for publication November 21, 2000.

Revision accepted March 8, 2001. 
W

HEN the laryngeal mask airway (LMA, The Laryngeal Mask Company Ltd., Henley on Thames, Oxon, UK) was introduced to manage the airway, it proved in addition to be a highly useful aid to fiberoptic intubation with a tracheal tube (TT). ${ }^{1}$ However, its construction imposed length/diameter limitations on the TTs that could be passed through it. ${ }^{1,2}$ The intubating laryngeal mask airway (ILMA, The Laryngeal Mask Company Ltd., Henley on Thames, Oxon, UK), introduced in 1997, allows easy passage of a well-lubricated $8.0 \mathrm{~mm}$ internal diameter (ID) cuffed TT, and it optimizes the angle at which the trachea is intubated. ${ }^{3-5}$ Yet, it has several disadvantages that become apparent with use: because of its cost, the ILMA may not always be available at every anesthesia work station; there are concerns about using the ILMA in patients with limited mouth opening $^{6-9}$ and in patients wearing semi-rigid neck collars. ${ }^{10}$ Additionally, the TT designed for use with the ILMA has a low volume/high pressure cuff and anesthesiologists are reluctant to use these TTs for prolonged periods. ${ }^{11}$ They ought to be replaced as soon as possible by a high volume/low pressure cuffed TT, but this manoeuver increases the risk of compromising the airway, especially in a patient with a difficult airway, and should be avoided if there is an alternative.

These disadvantages of the ILMA, which have been discussed recently in the literature, prompt us to report how an older technique, using a standard LMA as an intubation guide for $6 \mathrm{~mm}$ ID TTs in patients with difficult airways, can be adapted for $7 \mathrm{~mm}$ ID TTs.

\section{Case reports}

Case \#1

A 53-yr-old man, height $170 \mathrm{~cm}$, weight $80 \mathrm{~kg}$, body mass index 28 , presented with obstructive sleep apnea and subsequently underwent elective uvulopalatopharyngoplasty. The patient was classified as ASA score II and Mallampati score II. ${ }^{12} \mathrm{He}$ had normal teeth and a mouth opening of just under $25 \mathrm{~mm}$, full neck movement, a normal thyromental distance, and he denied any history of difficult intubation. His last previous anesthetic procedure, general anesthesia five years earlier, had been uneventful.

Following preoxygenation, anesthesia was induced with propofol $2 \mathrm{mg} \cdot \mathrm{kg}^{-1} i v$, midazolam $2 \mathrm{mg}$ iv followed by infusions of remifentanil $1.5 \mathrm{mg} \cdot \mathrm{hr}^{-1}$ and propofol $200 \mathrm{mg} \cdot \mathrm{hr}^{-1}$ iv. Bag-mask-valve ventilation was established and neuromuscular blockade was induced with mivacurium $0.2 \mathrm{mg} \cdot \mathrm{kg}^{-1}$. Laryngoscopy with Macintosh \#3 and \#4 blades showed only the tip of the epiglottis. Even repositioning of the head and
BURP $^{13}$ did not improve the laryngoscopic view. As ventilation by mask was easy and the patient was not at increased risk of aspiration of gastric contents, ${ }^{14}$ we decided to perform the tracheal intubation via an appropriately sized ILMA. However, it proved impossible to insert either a \#5 or a \#4 ILMA, because neither could be passed between the patient's teeth, despite twisting manoeuvres. Consequently, a standard \#4 LMA was prepared as a conduit for fiberoptic intubation. After we removed the \#4 LMA's connector, we preloaded a well-lubricated $7.0 \mathrm{~mm}$ nasal RAE $^{\mathrm{TM}}$ TT (Mallinckrodt Medical, Athlone, Ireland) into the LMA in the manner described by Benumof for a $6.0 \mathrm{~mm} \mathrm{TT}{ }^{1}$ Placing the LMA with the TT inside was very easy despite the patient's limited mouth opening. Subsequent fiberoptic-guided intubation via the \#4 LMA was easily performed as described by Benumof. ${ }^{1}$ The LMA was then removed over the TT, as we have done previously using microlaryngeal tubes, ${ }^{15}$ to enable surgery to proceed.

\section{Case \#2}

A 61-yr-old woman, height $165 \mathrm{~cm}$, weight $69 \mathrm{~kg}$, body mass index 25, presented with a loosened implant after left hip arthroplasty, and was scheduled for revision prosthesis. During the planning of perioperative management, the surgeon indicated that he anticipated surgery to last a minimum of four hours and to be attended by excessive blood loss. We thus decided to secure the patient's airway with an endotracheal tube (ETT). Because her neck movement was reduced after atlantoaxial stabilization several years earlier for atlantoaxial subluxation associated with rheumatoid arthritis, we anticipated intubation difficulties and planned awake securing of the airway. However, the patient adamantly refused both regional anesthesia and awake fiberoptic intubation. Following preoxygenation, anesthesia was induced with a total of $450 \mathrm{mg}$ thiopentone $i v$, followed by a total of $0.2 \mathrm{mg}$ fentanyl $i v$. Bag-mask-valve ventilation was established and neuromuscular blockade was induced with $8 \mathrm{mg}$ vecuronium $i v$. Because of the patient's limited neck movement, laryngoscopy with Macintosh \#3 and \#4 blades showed only the tip of the epiglottis. The laryngoscopic view did not improve even with repositioning of the head and BURP. ${ }^{13}$ Two attempts to visualize the laryngeal inlet with the fiberoptic bronchoscope (FOB) inserted nasally proved impossible because bloody secretions in the oropharynx obscured the FOB's tip. Ventilation by mask was easy and the patient was not at increased risk of aspiration of gastric contents; ${ }^{14}$ thus, we decided to perform the tracheal intubation via an appropri- 
ately sized laryngeal mask. Because there was no ILMA available, we used a standard LMA. The \#4 LMA did not provide sufficient manual ventilation, despite proper placement, because of severe air leakage. A \#5 LMA was easily inserted and functioned properly. We removed the LMA's connector, passed an $8.0 \mathrm{~mm}$ nasal $\mathrm{RAE}^{\mathrm{TM}} \mathrm{TT}$ through the LMA, easily performed fiberoptic-guided intubation, and removed the LMA over the TT as in Case \#1.

In both cases the remainder of the intraoperative course was uneventful.

\section{Discussion}

We have shown here that the LMA can be used in place of the ILMA as a guide to intubation with TTs of 7.0 and $8.0 \mathrm{~mm}$ ID if the connector is first removed. Removing the connector not only allows TTs of $>6.0 \mathrm{~mm}$ to pass through the mask, it also shortens the LMA's shaft, so that even standardlength TTs can be placed midtracheally via the LMA.

To manage the airway in our two patients when the ILMA failed or was unavailable, we returned to our former intubation strategy using the standard LMA. First, it is known that the LMA may be inserted even if the mouth opening is as little as $12 \mathrm{~mm},{ }^{14}$ and second, our observations, reported here, show that it is the connector that blocks the passage of ETTs $>6.0 \mathrm{~mm}$ ID through the LMA's airway tube, besides adding to its length. In a previous study we reported that repeated autoclaving impairs the connector-shaft bond of the LMA such that the connector can be deliberately twisted out of the shaft, but that the airtightness of the LMA is not thereby diminished. ${ }^{16}$ We also realized that we could pass larger-bore TTs through the mask when the connector was removed. Thus, we began to stock LMAs whose connector could be removed in our portable storage unit for difficult airway management. Whenever a LMA was to be used as a conduit for fiberoptic intubation, we used one from this stock and twisted the connector out. After the connector has been removed, a well-lubricated $7.0 \mathrm{~mm}$ TT of whatever type passes easily through a \#3 or \#4 LMA and any well-lubricated $8.0 \mathrm{~mm}$ TT through a \#5 LMA. Having high volume/low pressure cuffs, these TTs do not need to be replaced in case of prolonged intubation. ${ }^{11}$ Moreover, the sizes of these TTs, which are recommended as standard sizes for adults, ${ }^{17}$ are the same as those of the TTs passed via the ILMA. ${ }^{18}$ The mask can be removed over conventional-length 7.0 and $8.0 \mathrm{~mm}$ TTs with the help of any technique used by the individual anesthesiologist for $6 \mathrm{~mm}$ TTs.

We used the nasal RAE ${ }^{\mathrm{TM}}$ in the two cases presented here because previous successful experience with $6 \mathrm{~mm}$ microlaryngeal tubes ${ }^{15}$ had shown us that we could withdraw the LMA over these tubes with an extra margin of safety; at $40 \mathrm{~cm}$ they are some $11 \mathrm{~cm}$ longer than the conventional $6 \mathrm{~mm}$ ID tube. Having realized the advantages to be gained from removing the connector, we wanted to take this a step further. We thus looked for larger-bore tubes at a length comparable to the 6.0 $\mathrm{mm}$ microlaryngeal tubes and found the 7.0 and 8.0 $\mathrm{mm}$ nasal RAE ${ }^{\mathrm{TM}}$ TTs. At $37 \mathrm{~cm}$, the $7.0 \mathrm{~mm}$ nasal $\mathrm{RAE}^{\mathrm{TM}}$ tubes are $5.5 \mathrm{~cm}$ longer than a conventional TT of that ID and, at $39 \mathrm{~cm}$, the $8.0 \mathrm{~mm}$ nasal $\mathrm{RAE}^{\mathrm{TM}}$ tubes are $7.5 \mathrm{~cm}$ longer. Removal of the mask over the longer tubes differs in some detail from the methods compiled by Benumof ${ }^{1}$ and awaits further documentation by the authors.

While we originally saw removability of the connector as a potential risk, we have come to realize and utilize its benefits. Therefore, we recommend the use of standard LMAs with the connector removed, in combination with appropriately sized TTs, in situations in which the ILMA is disadvantageous or not available. Such standard LMAs may thus be a welcome supplement to ILMAs when fiberoptic intubation is contemplated.

Acknowledgement

We thank Jane Neuda for editorial assistance.

\section{References}

1 Benumof JL. Laryngeal mask airway and the ASA difficult airway algorithm. Anesthesiology 1996; 84: 686-99.

2 Asai T, Latto IP, Vaughan RS. The distance between the grille of the laryngeal mask airway and the vocal cords. Is conventional intubation through the laryngeal mask safe? Anaesthesia 1993; 48: 667-9.

3 Brain AIJ, Verghese C, Addy EV, Kapila A, Brimacombe $J$. The intubating laryngeal mask. II: a preliminary clinical report of a new means of intubating the trachea. $\mathrm{Br}$ J Anaesth 1997; 79: 704-9.

4 Brain AIJ, Verghese C, Addy EV, Kapila A. The intubating laryngeal mask. I: development of a new device for intubation of the trachea. Br J Anaesth 1997; 79: 699-703.

5 Brimacombe JR. Difficult airway management with the intubating laryngeal mask. Anesth Analg 1997; 85: 1173-5.

6 Asai T, Matsumoto H, Shingu K Awake tracheal intubation through the intubating laryngeal mask. Can J Anesth 1999; 46: 182-4.

7 Asai T, Shingu K Limited mouth opening and the intubating laryngeal mask (Letter). Can J Anesth 1999; 46: 807-8.

8 Brimacombe J, Keller C, Weidmann K Limited mouth opening and the intubating laryngeal mask. Can J Anesth 1999; 46: 807-8. 
9 Preis C, Czerny C, Preis I, Zimpfer M. Variations in ILMA external diameters: another cause of device failure. Can J Anesth 2000; 47: 886-9.

10 Wakeling HG, Nightingale J. The intubating laryngeal mask airway does not facilitate tracheal intubation in the presence of a neck collar in simulated trauma. Br J Anaesth 2000; 84: 254-6.

11 Honeybourne D, Costello JC, Barham C Tracheal damage after endotracheal intubation: comparison of two types of endotracheal tubes. Thorax 1982; 37: 500-2.

12 Mallampati SR, Gatt SP, Gugino LD, Waraksa B, Freiberger D, Liu PL. A clinical sign to predict difficult tracheal intubation: a prospective study. Can Anaesth Soc J 1985; 32: 429-34.

13 Knill RL. Difficult laryngoscopy made easy with a “BURP”. Can J Anaesth 1993; 40: 279-82.

14 Maltby JR, Loken RG, Beriault MT, Archer DP. Laryngeal mask airway with mouth opening less than $20 \mathrm{~mm}$. Can J Anaesth 1995; 42: 1140-2.

15 Preis CA, Preis IS. Oversize endotracheal tubes and intubation via laryngeal mask airway (Letter). Anesthesiology 1997; 87: 187.

16 Preis C, Hartmann T, Preis I, Wildling E, Gilly $H$. Autoclaving impairs the connector/tube bond of the laryngeal mask airway but not its airtightness. $\mathrm{Br} \mathrm{J}$ Anaesth 1998; 81: 795-6.

17 Larsen $R$ Anaesthesie. 5th Edition. München-WienBaltimore: Urban \& Schwarzenberg, 1995.

18 Joo HS, Rose DK The intubating laryngeal mask airway with and without fiberoptic guidance. Anesth Analg 1999; 88: 662-6. 